\title{
Smartphones for gestational diabetes in the COVID-19 era
}

\author{
loannis llias ${ }^{1}$ \\ Received: 11 November 2020 / Accepted: 21 December 2020 / Published online: 3 January 2021 \\ (C) Springer Nature Switzerland AG 2021
}

Keywords Gestational diabetes $\cdot$ COVID-19 $\cdot$ Smartphone $\cdot$ Photoplethysmography

Currently the worldwide COVID-19 pandemic has had a profound impact on the access to health services [1]. During pregnancy many women need to do an oral glucose tolerance test (OGTT); if positive, it rules in the diagnosis of diabetes in pregnancy. Since the access to health services under COVID19 may be compromised, authorities and experts have provided alternative approaches for the diagnosis of diabetes in pregnancy, using single glucose measurements or glycated hemoglobin (A1c) levels [2-6]. The relevant studies are few and their results may not apply to all populations. Overall these studies show that neither blood glucose and/or A1c can replace OGTT [7, 8]. However, serial blood glucose measurements can be very informative regarding the status of glycemia. Extremely low cost point of care devices could be used for measuring various metabolites, but their use is yet to be implemented widely [9]. Diabetes - apparently- can also be detected by applications using smartphone flashlight-enabled photoplethysmography (reported sensitivity is $75-81 \%$, specificity 54-65\%), as shown in a recent article [10]. Thus, affordable and accessible technology that can be used for the self-monitoring of blood glucose (SMBG) exists in smartphones. We can speculate that following a validation clinical trial, in lieu of an OGTT that necessitates the physical presence of pregnant women in a healthcare setting (with increased exposure to infection) assessment of glycemia in pregnancy could also be tried non-invasively at home. This may not be a lege artis approach but it is a practical one, given the current COVID-19 situation.

Author contributions I.I. conceived, researched and wrote this contribution.

Ioannis Ilias

iiliasmd@yahoo.com

1 Department of Endocrinology, Diabetes and Metabolism, Elena Venizelou Hospital, Athens GR-11521, Greece
Data availability Not applicable.

\section{Compliance with Ethical Standards}

Conflicts of interest/Competing interests None.

Ethics approval Not applicable.

Consent to participate Not applicable.

Consent for publication Not applicable.

Code availability Not applicable.

\section{References}

1. Sanjari M, Aalaa M, Ostovar A, Esfehani EN, Larijani B. Telehealth for fighting the novel coronavirus: review of activities on Diabetes and Osteoporosis management in outbreak. J Diabetes Metab Disord. 2020:1-2. https://doi.org/10.1007/s40200-02000562-9.

2. McIntyre HD, Gibbons KS, Ma RCW, Tam WH, Sacks DA, Lowe $\mathrm{J}$, et al. Testing for gestational diabetes during the COVID-19 pandemic. An evaluation of proposed protocols for the United Kingdom, Canada and Australia. Diabetes Res Clin Pract. 2020;167:108353. https://doi.org/10.1016/j.diabres.2020.108353.

3. Nouhjah S, Jahanfar S, Shahbazian H. Temporary changes in clinical guidelines of gestational diabetes screening and management during COVID-19 outbreak: A narrative review. Diabetes Metab Syndr. 2020;14(5):939-42. https://doi.org/10.1016/j.dsx.2020.06. 030.

4. Seshiah V, Balaji V, Banerjee S, Sahay R, Divakar H, Jain R, et al. Diagnosis and principles of management of gestational diabetes mellitus in the prevailing COVID-19 pandemic. Int J Diabetes Dev Ctries. 2020:1-6. https://doi.org/10.1007/s13410-020-008601 .

5. Thangaratinam S, Cooray SD, Sukumar N, Huda MSB, Devlieger R, Benhalima K, et al. ENDOCRINOLOGY IN THE TIME OF COVID-19: Diagnosis and management of gestational diabetes mellitus. Eur J Endocrinol. 2020;183(2):G49-56. https://doi.org/ 10.1530/eje-20-0401.

6. Torlone E, Festa C, Formoso G, Scavini M, Sculli MA, Succurro E, et al. Italian recommendations for the diagnosis of gestational 
diabetes during COVID-19 pandemic: Position statement of the Italian Association of Clinical Diabetologists (AMD) and the Italian Diabetes Society (SID), diabetes, and pregnancy study group. Nutr Metab Cardiovasc Dis. 2020;30(9):1418-22. https:// doi.org/10.1016/j.numecd.2020.05.023.

7. van Gemert TE, Moses RG, Pape AV, Morris GJ. Gestational diabetes mellitus testing in the COVID-19 pandemic: The problems with simplifying the diagnostic process. Aust N Z J Obstet Gynaecol. 2020. https://doi.org/10.1111/ajo.13203.

8. van-de-l'Isle Y, Steer PJ, Watt Coote I, Cauldwell M. Impact of changes to national UK Guidance on testing for gestational diabetes screening during a pandemic: a single centre observational study. BJOG. 2020. https://doi.org/10.1111/1471-0528.16482.

9. Omidfar K, Ahmadi A, Syedmoradi L, Khoshfetrat SM, Larijani B. Point-of-care biosensors in medicine: a brief overview of our achievements in this field based on the conducted research in EMRI (endocrinology and metabolism research Institute of Tehran University of medical sciences) over the past fourteen years. J Diabetes Metab Disord. 2020:1-5. https://doi.org/10.1007/ s40200-020-00668-0.

10. Avram R, Olgin JE, Kuhar P, Hughes JW, Marcus GM, Pletcher $\mathrm{MJ}$, et al. A digital biomarker of diabetes from smartphone-based vascular signals. Nat Med. 2020. https://doi.org/10.1038/s41591020-1010-5.

Publisher's note Springer Nature remains neutral with regard to jurisdictional claims in published maps and institutional affiliations. 